\author{
Чжао Лян \\ Белорусский государственный университет
}

\title{
АКТУАЛЬНЫЕ НАУЧНЫЕ ПОДХОДЫ К МОДЕЛИРОВАНИЮ СОВРЕМЕННОЙ КОНЦЕПЦИИ ТЕОРИИ МЕДИАТИЗАЦИИ
}

Изобретение фотографии, электричества, кинематографа, радиовещания, цветной печати, первые эксперименты с телевидением - все это на рубеже XIX-XX вв. обусловило развитие комплекса наук о коммуникации с выделением такой ее формы, как массмедиа. К массмедиа традиционно относят книжные и газетные издательства, информационные агентства, редакции прессы, радиовещания, телевидения, кино-, видео-, звукозаписывающие компании, которые имеют соответствующую материально-техническую инфраструктуру.

В статье рассматриваются современные подходы к определению терминов «медиа» и «медиатизация». В компаративном контексте анализируются взгляды авторитетных исследователей на сущность медиатизации, влияние этого процесса на развитие общества, его отдельных сфер. Характеризуется состояние развития теории медиатизации в англо- и русскоязычном научном дискурсе, китайской социальной науке, описывается практика проведения научных конференций, стратегически ориентированных исследований в рамках определенных программ, посвященных изучению феномена медиатизации.

Многие эмпирические исследования не имеют прочной связи с теорией медиатизации. Одним словом, теория медиатизации находится в процессе бурного развития, однако сущностное ее понимание еще недостаточно определено. А с началом XXI в. новым этапом в разработке и систематизации теории медиатизации стала практика проведения научных конференций, стратегически ориентированных исследований в рамках определенных программ.

Ключевые слова: коммуникация, медиа, медиатизация, теория медиатизации, массмедиа.

Для цитирования: Лян Ч. Актуальные научные подходы к моделированию современной концепции теории медиатизации // Труды БГТУ. Сер. 4, Принт- и медиатехнологии. 2021. № 2 (249). C. $77-83$.

\section{Chzhao Lyan \\ Belarusian State University \\ ACTUAL SCIENTIFIC APPROACHES TO MODELING THE MODERN CONCEPT OF THE THEORY OF MEDIATIZATION}

The invention of photography, electricity, cinema, radio broadcasting, color printing, the first experiments with television - all this at the turn of the XIX-XX centuries led to the development of a complex of communication sciences with the allocation of such a form as mass media. The mass media traditionally includes book and newspaper publishers, news agencies, editorial offices of the press, radio broadcasting, television, film, video, and sound recording companies that have the appropriate material and technical infrastructure.

The article discusses modern approaches to the definition of the terms "media" and "mediatization". In a comparative context, the author analyzes the views of authoritative researchers on the essence of mediatization, the impact of this process on the development of society and its individual spheres. The state of development of the theory of mediatization in the English and Russian-language scientific discourse, Chinese social science is characterized, the practice of holding scientific conferences, strategically oriented research within the framework of certain programs devoted to the study of the phenomenon of mediatization is described.

Many empirical studies do not have a strong connection with the theory of mediatization. In a word, the theory of mediatization is in the process of rapid development, but its essential understanding is not yet sufficiently defined. And since the beginning of the XXI century, a new stage in the development and systematization of the theory of mediatization has become the practice of holding scientific conferences, strategically oriented research within the framework of certain programs.

Key words: communication, media, mediatization, theory of mediatization, mass media.

For citation: Lyan Ch. Actual scientific approaches to modeling the modern concept of the theory of mediatization. Proceedings of BSTU, issue 4, Print-and Mediatechnologies, 2021, no. 2 (249), pp. 77-83 (In Russian). 
Введение. Общепринятое определение человека как социального существа дает ученому фундаментальную отправную точку для начала любого исследования в области гуманитарных наук. В цивилизациях Древнего мира активное участие индивидуума в жизни общества считалось неоспоримой добродетелью, а в Афинах граждан, избегавших посещения публичных мероприятий, подвергали остракизму, изгоняли за пределы полиса. С развитием человечества социальная значимость общения, информации и коммуникации неуклонно возрастала, достигнув своего пика в настоящее время, когда даже такие глобальные кризисные явления, как пандемия коронавируса, ограничивая этот процесс в офлайнформате, стимулируют его в виртуальной среде.

Термин «медиа» (от medium) в переводе с латыни обозначает середину, посредничество, среду. Широкое распространение он получил в 1860-е гг., когда в США стало модным посещать платные спиритические сеансы общения с душами умерших. Подобные сеансы ознаменовали зарождение общества массового потребления и массовой культуры, которыми сопровождался переход промышленно развитых западных стран к периоду научно-технического прогресса. Изобретение фотографии, электричества, кинематографа, радиовещания, цветной печати, первые эксперименты с телевидением все это на рубеже XIX-XX вв. обусловило развитие комплекса наук о коммуникации с выделением такой ее формы, как массмедиа. К массмедиа традиционно относят книжные и газетные издательства, информационные агентства, редакции прессы, радиовещания, телевидения, кино-, видео-, звукозаписывающие компании, которые имеют соответствующую материальнотехническую инфраструктуру.

Основная часть. В современной теории коммуникации и массмедиа особое внимание уделяется исследованиям медиатизации, иначе говоря, социальным последствиям оперирования информацией, когда она рассматривается как объективная первооснова всех процессов жизнедеятельности государства, общества и человека. В этом контексте датский ученый Йенсен К. Б. разделил медиа на три группы. Первые дают возможность человеку самостоятельно или вместе с другими людьми познавать действительность для осуществления жизнедеятельности: устная и письменная формы языка, научное и художественное творчество. Медиа второй категории, в функционировании которых используется техника, позволяют в значительной степени преодолевать два главных барьера в процессе коммуникации - пространство и время (разовые и периодические печатные издания, радио, кино, телевидение). Медиа третьего уровня основаны на цифровых информационно- коммуникационных технологиях. Они создают сильную конкуренцию традиционным средствам массовой коммуникации, но у последних есть возможность на равных соревноваться с ними в глобальной сети. Датский ученый особо подчеркивает такой важный аспект, как влияние процесса развития медиа на общество. «Каждый из этих типов медиа способствует социальному структурированию определенным образом, и они делают это, участвуя в производстве и распространении в обществе значения, которое накапливается как культура» [1].

Среди множества школ теории коммуникаций для нас наибольший интерес представляет Торонтская, поскольку именно ее представители (Г. Иннис, М. Маклюэн, У. Дж. Онг, Б. Андерсон и другие ученые) наиболее глубоко и всесторонне занимались изучением феномена медиа, а также его корреляций с прогрессом цивилизации. Именно Г. Иннис в конце 1950-х гг. одним из первых начал комплексно исследовать взаимозависимость между типом социальной организации и системой массовой коммуникации. Основной вывод ученого состоял в том, что каждый исторический период сопровождается стремлением властных структур установить монополию над СМК, а объективным решением этих проблем становится появление в результате технического прогресса нового типа медиа, что влечет за собой значительные изменения в политической, экономической, культурной, идеологической сферах жизни общества [2].

Наиболее известным представителем Торонтской школы теории коммуникаций стал Маршалл Маклюэн, который в работах «Галактика Гутенберга: Становление человека печатающего» (The Gutenberg Galaxy: The Making of Typographic Man) 1962 г., «Понимание медиа: Внешние расширения человека» (Understanding Media: The Extensions of Man ) 1964 г., «Медиа это сообщение: Перечень последствий» (The Medium Is the Massage: An Inventory of Effects, with Quentin Fiore) 1967 г., «Война и мир в глобальной деревне» (War and Peace in the Global Village) 1968 г. изложил свои достаточно оригинальные взгляды относительно влияния медиа на общество и личность человека. Начав исследовательскую деятельность с изучения феномена массовой культуры, М. Маклюэн выдвинул ряд неоднозначных суждений, которые до сих пор вызывают дискуссии. Вместе с тем, несмотря на парадоксальность некоторых выводов, работы Маклюэна намного опередили свое время.

Определения медиа, которые он предложил, допускают достаточно широкое толкование. Под медиа сегодня понимается система массовой коммуникации, когда в широкой трактовке посредническая функция в общении человека с другими людьми и внешней средой может выполняться

Труды БГТУ Серия 4 № 22021 
не только человеком, но и любыми искусственно созданными объектами. В этом случае такими объектами служат различные созданные людьми технические средства, помогающие обмену информацией между внутренним миром индивидуума и социальным миром [3, с. 32].

Мы согласны с мнением российского исследователя Дукина Р. А., что в русскоязычном научном сообществе термин «медиа» чаще интерпретируется как «средства коммуникации» [4, с. 24-26]. В современной науке существует большое количество подходов к пониманию сущности медиатизации. Как справедливо отмечает научный сотрудник кафедры теории и экономики СМИ факультета журналистики МГУ имени М. В. Ломоносова Гуреева А. Н., «терминологически понятие «медиатизации» зачастую отождествляют со схожими по звучанию понятиями «медиазации» и «медиатации». Подобные термины, которых в условиях развития медиа сегодня огромное множество, - «медиация», «медиатизация», «медиазация» и «медиализация» порождают многочисленные дискуссии и разнообразные интерпретации в связи с языковыми различиями исследователей и спецификой конкретного перевода» [5, с. 192-208]. Хотя все четыре варианта пришли из англоязычной науки, нам это напоминает аналогичную ситуацию в русскоязычной теории коммуникации, когда ученые ведут многолетние дискуссии, стремясь найти различия между терминами «имидж» и «образ», тогда как в англоязычной науке такой «проблемы» не существует. Поэтому представляется целесообразным сосредоточиться на одном термине «медиатизация» с целью достижения наиболее объективного и конкретного результата исследования двустороннего процесса корреляции медиа и различных сфер жизнедеятельности общества, в ходе которого они оказывают друг на друга постоянное и существенное влияние.

Считается, что первым термин «медиатизация» применил Дж. Б. Томпсон, который в работе The Media and Modernity: A Social Theory of the Media [6] отметил возрастающее влияние медиа на общество. Со временем изучение феномена медиатизация стала важной частью современных исследований коммуникации, объектом которых является трансформация общества, в первую очередь политики, под влиянием медиа, а предметом - закономерности и механизмы этого взаимовлияния с возрастанием доминирующих средств массовой коммуникации, особенно новых медиа. Если британский социолог рассматривал медиатизацию в рамках общекультурных процессов, то шведский исследователь Кент Асп первым стал изучать влияние СМИ на политическую жизнь, когда «политическая система в значительной степени находится под влиянием и приспосабливается к требованиям средств массовой информации в их освещении политики» $[7$, c. 336].

К. Асп полагает, что процесс медиатизации политики развивается при таких условиях, когда СМИ являются основным или единственным источником политической информации и в связи с этим могут влиять и в значительной степени формировать представления публики о политической реальности. Следует отметить, что единственным источником информации СМИ в действительности быть не могут, поскольку всегда существуют другие, формальные и неформальные каналы коммуникации. Основные положения теории К. Аспа о влиянии СМИ на политические процессы получили свое развитие в работах других исследователей.

Так, датский ученый Стиг Хьярвард считает, что медиатизация является социальным процессом, при котором средства массовой коммуникации настолько внедрены в общественную жизнь, что они не могут рассматриваться отдельно от других институтов общества [8, с. 9 26]. Возрастающая зависимость социума от медиа и особенностей их функционирования, по мнению С. Хьярварда, с аксиологической точки зрения имеет одновременно позитивные и негативные последствия. Это объясняется комплексом объективных причин: ослаблением регулирующей роли государства, снижением действенности этических норм и кодексов, произвольным характером направлений и различными уровнями развития самой медиасреды. Хьярвард отмечает, что использование публичной персоной медиума, например аккаунта в социальной сети или блога, не всегда оказывает существенное влияние на политику как сферу деятельности. Это только частное проявление глобального процесса медиатизации, в ходе которого социальные структуры и способы их взаимодействия с гражданами и между собой меняются под воздействием прогресса информационно-коммуникационных технологий. С помощью таких технологий люди изменяют все сферы общественной жизни, что в итоге оказывает значительное влияние на формирование и отражение общественного мнения, группового и индивидуального сознания [9, c. 105-134]. Поэтому Хьярвард считает, что теория медиатизации должна изучать существенные тенденции трансформации общества в контексте возрастающего воздействия медиа на социальные институты и области человеческой деятельности.

Оригинальный подход к пониманию медиатизации предложил немецкий ученый Винфрид Шульц, занимающийся исследованиями методов коммуникации, закономерностей влияния средств массовой информации на политику. 
Анализируя закономерности корреляции СМИ и общества, он выделил четыре основных функциональных вида взаимодействия: расширение, замещение, объединение, приспособление $[10$, c. 87-101]. Развивая суждение М. Маклюэна о том, что «медиа - это внешнее расширение человека», В. Шульц утверждает, что общение людей ограничено пространством, временем и средствами выразительности. Средства массовой коммуникации уменьшают эти барьеры, одновременно расширяя парадигму выразительных средств человека.

Замещение рассматривается в двух аспектах: управленческом и представительском. В первом случае оно касается замены устаревших, не связанных с массмедийной деятельностью форм и методов работы различных общественных институтов. Во втором речь идет о выполнении медийной организацией как частью более крупной структуры представительских функций связей с внешней средой. Например, пресс-служба компании распространяет официальную информацию от лица всей компании, а отдельные редакции, являясь только частью национальной системы СМИ, претендуют на выражение общественного мнения в целой стране.

Благодаря использованию медиа происходит объединение относящихся и не относящихся к массовой информации видов деятельности с целью достижения наиболее оптимальных результатов как внутри организации (корпоративные медиа), так и вне ее - продвижение товаров и услуг, реклама, связи с общественностью и т. д. По этому поводу Билл Гейтс сказал: «В будущем на рынке останется два вида компаний: те, кто в Интернете, и те, кто вышел из бизнеса» [11].

Согласно «институционалистской» концепции средства массовой информации устанавливают нормы социального взаимодействия (медиалогику), к которым объективно вынуждены приспосабливаться, адаптироваться различные общественные институты. Именно с медиалогикой В. Шульц связывает долгосрочные социально-культурные изменения, утверждая, что у общества нет другой альтернативы, кроме как в дальнейшем подчиниться ей.

Основными представителями этой школы медиатизации являются Дэвид Алтейд и Роберт Сноу, которые обосновали термин «медиалогика» в 1979 г. Они считали, что логика СМИ формирует фонд знаний, который генерируется и распространяется в обществе. Д. Алтейд и Р. Сноу предположили, что медиалогика преимущественно включает в себя закономерности форматирования информации, которые определяют, как классифицируется материал, выбор способа его представления в средствах массовой информации и другие характеристики. Вслед за институционалистской С. Хьярвард выделил в зарубежной теории медиатизации еще несколько школ, отличающихся между собой подходами к анализу причин возникновения и закономерностям развития исследуемого процесса [12]. Социально-конструктивистская концепция основывается на понимании медиатизации как социального и культурного процесса. Сторонники этого подхода критикуют медийную логику, утверждая, что бессмысленно описывать специфику, которую определенная среда может иметь сама по себе. Источник возрастающего влияния СМИ, по их мнению, заключается только в практической деятельности медиа, которая понимается не как причинность или просто действие, но как сила, формирующая действия по определенным шаблонам. Теория социального конструктивизма ставит своей целью понять, как производится и воспроизводится влияние средств массовой коммуникации через практику социального взаимодействия.

Материалистическая школа изучает влияние средств массовой информации в общей перспективе. Основное внимание здесь уделяется тому, как отдельные виды средств массовой информации оказывают воздействие на социальное устройство, технологический характер отношений человека с другими членами общества. Эта теория исходит из утверждения, что конкретные медиатехнологии, например издательские или телевизионные, следует рассматривать как ключевой фактор в формировании общества нового типа.

Если все вышеперечисленные школы рассматривают медиа в качестве субъекта воздействия, а общество - как его объект, то социокультурный подход основывается еще и на исследовании взаимосвязи между изменениями системы средств массовой коммуникации и социокультурными изменениями в практике разного рода общения, в коммуникативной модели действительности. В реальности массмедиа не обязательно всегда вызывают преобразования, но они стали важнейшей составной частью коммуникации личности, групп, организаций, стран и регионов в сфере политики, экономики, образования, здравоохранения и других с внешней средой. Социокультурный подход в теории медиатизации основан на исследовании способов встраивания СМК в культурные трансформации, влияния на взаимосвязи между различными видами культуры, например, доминирующей и субкультур. Такой анализ показывает, что медиатизация субкультурных групп в большинстве случаев приводит к тому, что они становятся частью основной культуры, меняют свой неформальный имидж и вовлекаются в процесс коммерциализации.

С. Хьярвард и Л. Н. Петерсен обобщили роль медиа в социокультурных изменениях следующим образом: «(1) Когда различные формы субкультур 
пытаются использовать средства массовой информации в своих собственных целях, они часто становятся (повторно) встроенными в основную культуру; 2) Национальная культурная политика часто служит рычагом для усиления медиатизации; (3) Медиатизация влечет за собой трансформацию способов осуществления управления и контроля, приобретения и защиты репутации в обществе; и (4) Технологические разработки формируют возможности медиа и, таким образом, являются отдельной частью процесса медиатизации» [13, с. 1-7]. В русскоязычной коммуникативистике понятие «медиатизации» впервые было использовано в 1991 г. в научно-аналитическом обзоре Т. В. Андриановой и А. И. Ракитова «Современные тенденции информатизации и медиатизации общества». Авторы охарактеризовали медиатизацию как составную часть процесса информатизации общества с рыночной экономикой. Данный процесс объективно необходим потому, что субъекты экономической деятельности для обеспечения своего устойчивого функционирования должны постоянно производить и потреблять все возрастающее количество информации. Со временем медиатизация распространяется практически на все сферы жизнедеятельности общества, в частности, она влияет на «содержание массовой культуры и культуры элитарной, их пропорции и взаимоотношения качественно меняются» [14, c. 117]. По мере качественного изменения и увеличения масштаба процесса медиатизации на практике возрастало и внимание к нему исследователей, активизировалась попытки его теоретического осмысления. Среди ученых, занимающихся научной разработкой данного феномена, следует назвать Анохину В. В., Гурееву А. Н., Дукина Р. А., Загиддулину М. В., Землянову Л. М., Рогозину И. В., Почепцова Г. Г., Шаронова Д. И. и многих др. Сегодня в широком смысле под медиатизацией понимают многогранное влияние медиа на социум в целом или на его отдельные страты, а также на человека в процессе коммуникации. Исследователь Рогозина И. В., например, дает такое определение медиатизации: «Это процесс и результат глобального воздействия на мышление индивидов при помощи различных медиа, выражающегося в формировании картины мира посредством специфических медийных когнитипов...» [15, с. 120-126].

Развивая данный аспект теории медиатизации, профессор Вартанова Е. Л. предложила свое определение современного индивидуума как человека медийного. «Сама идея «человека медийного» - это идея человека, существование которого напрямую формируется процессом получения, потребления и осмысления медиатизированной информации, медийной средой, и социальное, индивидуальное бытование фактически реализуется в информационных и коммуникационных процессах» [16]. Такой индивидуум активно коммуницирует в медиапространстве, где функционируют как традиционные газеты, журналы, радиовещание и телевидение, так и новые медиа. Современного человека невозможно исключить из того в значительной степени медиатизированого социального пространства, в котором он живет.

A белорусский исследователь Пивоварчик Т. А. отмечает поведенческие аспекты влияния медиатизации на личность: «если традиционно коммуникативная активность или пассивность человека интерпретировалась, прежде всего, как индивидуальное качество личности, то сегодня медиатизированная действительность «навязывает» характер и способы коммуникативной активности человека, оказывается сильнее, чем его природная предрасположенность. Наличие доступных сервисов (например, генераторов мемов) подвигает человека к расширению способов его коммуникативной активности» [17, с. 149-152].

Объединяя индивида и общество как объекты воздействия медиа, российский исследователь Загидуллина М. В. вводит в научный оборот понятие «панмедиатизация», которым обозначает «проникновение медиа во все сферы деятельности человека, в том числе сферу межперсонального общения, личного пространства и повседневных практик, ранее осуществлявшихся без посредников либо опиравшихся на посредничество медиумов неэлектронного типа (например, печатных книг)» [18, c. 60-77]. А сторонница культурологического подхода Землянова Л. М. предлагает термин «мультимедиатизация» для характеристики способности медиа видоизменять общественные представления о реальности и подчинять своим имиджам массовую аудиторию. Одной из существенных характеристик массмедиа она считает их способность оперативно передавать информацию на большие пространства, оказывая влияние на «морфологию современной культуры, ее содержание, функции и власть над умами» [19, с. 159].

Все это многообразие теоретических подходов к изучению процесса медиатизации пока не характерно для комплекса социально-гуманитарных наук в КНР. Как отмечает исследователь Буридэ, «китайские ученые довольно поздно столкнулись с теорией медиатизации. Несмотря на то, что в 2000-х гг. такие исследователи, как Ся Вэньжун, Тун Бин, Чжан Таофу, Чжан Сяофэн, Цюань Янь, Шэнь Фань, Фан Янь опубликовали работы на схожие темы, они в то время рассматривали медиатизацию узко - как феномен СМИ - без определенной теоретической коннотации, так что напрямую это не было связано с европейскими коммуникативными исследованиями. Вслед за 
бурной дискуссией о медиатизации западного толка в 2014 г. китайские ученые начали активно переводить западные труды по медиа и коммуникации, осознанно знакомить коллег с названным феноменом. .... Тан Шичжэ, Пань Чжундан, Чжоу Сян, Ли Цзя также предложили интерпретацию концепций медиатизации, медиалогии, метапроцесса, трансформации социального пространства.... В последние пять лет в Китае наблюдается нехватка теоретических и эмпирических исследований по теме. Вместе с тем многие эмпирические исследования не имеют прочной связи с теорией медиатизации. Одним словом, теория медиатизации находится в процессе бурного развития, однако сущностное ее понимание еще недостаточно определено.» [20, с . 289].

Заключение. C началом XXI в. новым этапом в разработке и систематизации теории медиатизации стала практика проведения научных конференций, стратегически ориентированных исследований в рамках определенных программ. С 2010 по 2016 г. при финансовой поддержке Исследовательского общества Германии реализовывалась международная программа Mediatized Worlds, координатором которой был професcop Кротц Ф. (Friedrich Krotz), глава Центра медиа, коммуникационных и информационных исследований Университета Бремена.

При Европейской ассоциации исследований коммуникации и образования (European Communication Research and Education Association, ECREA) создано отделение Mediatization, по инициативе которого были проведены конференции «Медиатизация в глобальной перпективе: сравнение теоретических подходов в цифровом мире (Лиссабон, 2017), «Доверие, контроль и конфиденциальность: медиатизация детства и подростков в цифровую эпоху» (Прага, 2018). Также издается в электронном формате на базе Университета Стамбула тематический сборник New Media / New Society?.

\section{Список литературы}

1. Клаус Б. Дж., Николас В. Дж. Справочник по коммуникационным исследованиям: качественные и количественные методологии. Лондон: Taylor \& Francis, 2002. 268 c.

2. Гарольд А. И. Империя и коммуникации. Торонто: Dundurn Пресс, 2007. 288 с.

3. Роберт К. Л. Неправильное понимание Маклюэна: установление рекорда прямо. Торонто: Kindle Edition, 2013. 199 c.

4. Дукин Р. А. Медиатизация современного общества: влияние социальных медиа // Theory and practice of social development. 2016. No. 2. C. 24-26.

5. Гуреева А. Н. Теоретическое понимание медиатизации в условиях цифровой среды // Journal Moscow Sate University. 2016. No. 10. C. 192-208.

6. Беверли М. Э. Кембридж: политика. Стэнфорд: Стэнфордский университет, 1995. 337 с.

7. Олаф Хоффьянн, Роланд Шталь. Руководство по связям с общественностью. Висбаден: Nabu Press, 2010. $459 \mathrm{c}$.

8. Хьярвард С. Медиатизация религии: теория СМИ как агентов религиозных изменений // Northern Lights: Film \& Media Studies Yearbook. 2008. No. 6. C. 199.

9. Хьярвард С. Медиатизация общества: теория СМИ как агентов социальных и культурных изменений // Nordicom Review. 2008. No. 2. C. 105-134.

10. Шульц В. Реконструкция медиатизации как аналитической концепции // European Journal of Communication. 2004. No. 1. P. 87-101.

11. Билл Гейтс Цитаты Билла Гейтса [Электронный ресурc]. URL: https://socratify.net/quotes/billgeits/114989 (дата обращения: 05.07.2021).

12. Хьярвард С. Медиатизация культуры и общества. Лондон: Routledge, 2013. 192 с.

13. Хьярвард С., Ниброс Л. Medie / Kultur. Медиатизация и культурные изменения Петерсен // Journal of media and communication research. 2013. No. 54. C. 1-7.

14. Андрианова Т. В., Ракитов А. И. Современные тенденции информатизации и медиатизации общества. М.: ИНИОН, 1991. 117 с.

15. Рогозина И. В. Функции и структура медиакартины мира // Methodology of modern psycholinguistics, 2003. C. 120-126.

16. Вартанова Е. Л. «Человек медийный» - новая ступень эволюции или приложение к гаджету? [Электронный ресурc]. URL: https://www.nkj.ru/open/27523/ (дата обращения: 05.07.2021).

17. Пивоварчик Т. А. Медиатизация как фактор развития коммуникативной активности личности // Корпоративные стратегические коммуникации: новые тренды в профессиональной деятельности: материалы II Междунар. науч.-практ. конф. Минск, 2018. С. 149-152.

18. Загидуллина М. В. Интермедиальность в эпоху тотальной медиатизации: как технологии влияют на литературу и ее теорию // Павермановские чтения. Литература. Музыка. Театр: сб. науч. трудов. 2017. С. 60-77. 
19. Землянова Л. М. Гуманитарная миссия современной глобализирующейся комуникативистики. М.: Московский университет, 2010. 272 с.

20. Буридэ. Концепт «медиатизация» в современных китайских исследованиях // Сб. науч. статей студентов, магистрантов, аспирантов. 2019. Вып. 22. 372 с.

\section{References}

1. Klaus B. J., NicholasW J. A Spravochnik po kommunikatsionnym issledovaniyam: kachestvennyye $i$ kolichestvennyye metodologii [Handbook of Communication Research: Qualitative and Quantitative Methodologies]. London, Taylor \& Francis Publ., 2002, 268 p.

2. Harold A. I. Imperiya i kommunikatsii [Empire and Communications]. Toronto, Dundurn Press, 2007, 288 p.

3. Robert K. L. Nepravil'noye ponimaniye Makluena: ustanovleniye rekorda pryamo [McLuhan Misunderstood: Setting the Record Straight]. Toronto, Kindle Edition Publ., 2013, 199 p.

4. Dukin R. A. Mediatization of Modern Society: The Impact of Social Media. Theory and practice of social development, 2016, no. 2, pp. 24-26 (In Russian).

5. Gureeva A. N. Theoretical understanding of mediatization in the digital environment. Journal Moscow Sate University, 2016, no. 10, pp. 192-208 (In Russian).

6. Beverly M. E. Kembridg: politika [Cambridge: politics]. Stanford, Stenfordskiy universitet Publ., 1995. 337 p.

7. Hoffjann O., Roland S. Rukovodstvo po svyazyam s obshchestvennost'yu [Association communication manual]. Wiesbaden, Nabu Press Publ., 2010. 459 p.

8. Hjarvard S. The Mediatization of Religion: A Theory of the Media as Agents of Religious Change. Northern Lights: Film \& Media Studies Yearbook, 2008, vol. 6, no. 1. P. 199 (In Russian).

9. Hyarvard S. The mediatization of society: A theory of the media as agents of social and cultural change. Nordicom Review, 2008, no. 2, pp. 105-134 (In Russian).

10. Schults W. Reconstructing mediatization as an analytical concept. European Journal of Communication, 2004, no. 1, pp. 87-101 (In Russian).

11. Bill Gates. Tsitaty Billa Geytsa [Quotes of Bill Gates]. Available at: https://socratify.net/quotes/billgeits/114989 (accessed 05.07.2021).

12. Stig Hjarvard. Mediatizatsiya kul'tury i obschestva [The Mediatization of Culture and Society]. London, Routledge Publ., 2013. 192 p.

13. Medie Kultur. Mediatization and Cultural Change by Stig Hjarvard and Line Nybro Petersen. Journal of media and communication research, 2013, no. 54, pp. 1-7 (In Russian).

14. Andrianova T. V., Rakitov A. I. Sovremennyye tendentsii informatizatsii i mediatizatsii obschestva [Modern trends in informatization and mediatization of society]. Moscow, UNION Publ., 1991. $117 \mathrm{p}$.

15. Rogozin I. V. Functions and structure of the media picture of the world. Methodology of modern psycholinguistics, 2003, pp. 120-126 (In Russian).

16. Vartanova E. L. "Chelovek mediynyy - novaya stupen' evolutsii ili prilozheniye k gadzhetu?" ["Media Man" - a New Stage of Evolution or an Application to a Gadget?]. Available at: https://www.nkj.ru/open/27523/ (accessed 05.07.2021).

17. Pivovarchik T. A. Mediatization as a factor in the development of a person's communicative activity. Materialy II Mezhdunar. nauch.-prakt. konf. "Korporativnyye strategicheskiye kommunikatsii: novyye trendy v professional'noy deyatel'nosti" [Second International Scientific and Practical Conference "Corporate strategic communications: new trends in professional activity"]. Minsk, 2018, pp. 149-152 (In Russian).

18. Zagidullina M. V. Intermediation in the era of total mediatization: how technologies affect literature and its theory. Sb. nauch. trudov "Pavermanovskiye chteniya. Literatura. Muzyka. Teatr" [International Scientific and Practical Conference "Powerman readings. Literature. Music. Theatre"]. Moscow, 2017, pp. 60-77 (In Russian).

19. Zemlyanova L. M. Gumanitarnaya missiya sovremennoy globaliziruyushcheysya komunikativistiki [Humanitarian mission of modern globalizing communication science]. Moscow, Moscovskiy Universitet Publ., 2010, 272 p.

20. Buride The concept of "mediatization" in contemporary Chinese studies. Sb. nauchnykh statey studentov, magistrantov, aspirantov [Collection of scientific articles of students, undergraduates, graduate students]. Minsk, 2019. 372 p. (In Russian).

\section{Информация об авторе}

Чжао Лян - аспирант кафедры медиалогии. Белорусский государственный университет (220004, г. Минск, ул. Кальварийская, 9, Республика Беларусь). E-mail: zhaoliangabcd@gmail.com

\section{Information about the author}

Chzhao Lyan - PhD student, the Department of Media Theory. Belarusian State University (9, Kalvariyskaya str., 220004, Minsk, Republic of Belarus). E-mail: zhaoliangabcd@gmail.com 